\title{
BMJ Open Relationship between acute pain trajectories after an emergency department visit and chronic pain: a Canadian prospective cohort study
}

\author{
Raoul Daoust (10 ,1,2 Jean Paquet, ${ }^{1}$ Alexis Cournoyer, ${ }^{2,3}$ Éric Piette, ${ }^{2}$ Judy Morris, ${ }^{3}$ \\ Justine Lessard, ${ }^{1,2}$ Gilles Lavigne, ${ }^{4}$ Jean-Marc Chauny ${ }^{3}$
}

To cite: Daoust R, Paquet J, Cournoyer A, et al. Relationship between acute pain trajectories after an emergency department visit and chronic pain: a Canadian prospective cohort study. BMJ Open 2020;10:e040390. doi:10.1136/ bmjopen-2020-040390

- Prepublication history and additional material for this paper is available online. To view these files, please visit the journal online (http://dx.doi.org/10. 1136/bmjopen-2020-040390).

Received 13 May 2020 Revised 05 November 2020 Accepted 09 November 2020

Check for updates

(c) Author(s) (or their employer(s)) 2020. Re-use permitted under CC BY-NC. No commercial re-use. See rights and permissions. Published by BMJ.

${ }^{1}$ Emergency, Hopital du SacreCoeur de Montreal Centre de Recherche, Montreal, Quebec, Canada

${ }^{2}$ Faculte de medecine, Université de Montréal, Montréal, Quebec,

Canada

${ }^{3}$ Department of Emergency Medicine, Hopital du SacreCoeur de Montreal, Montréal, Quebec, Canada

${ }^{4}$ Médecine Dentaire, Université de Montréal, Montreal, Quebec, Canada

Correspondence to

Dr Raoul Daoust;

raoul.daoust@videotron.ca

\section{ABSTRACT}

Objectives Inadequate acute pain management can reduce the quality of life, cause unnecessary suffering and can often lead to the development of chronic pain. Using group-based trajectory modelling, we previously identified six distinct pain intensity trajectories for the first 14-day postemergency department (ED) discharge; two linear ones with moderate or severe pain during follow-up ( $40 \%$ of the patients) and four cubic polynomial order trajectories with mild or no pain at the end of the 14 days (low final pain trajectories). We assessed if previously described acute pain intensity trajectories over 14 days after ED discharge are predictive of chronic pain 3 months later.

Design Prospective cohort study.

Setting Tertiary care trauma centre academic hospital. Participants This study included 18 years and older ED patients who consulted for acute ( $\leq 2$ weeks) pain conditions that were discharged with an opioid prescription. Patients completed a 14-day diary in which they listed their daily pain intensity $(0-10$ numeric rating scale).

Outcomes Three months after ED visit, participants were questioned by phone about their current pain intensity (0-10 numeric rating scale). Chronic pain was defined as patients with current pain intensity $\geq 4$ at 3 months. Results A total of 305 participants remained in the study at 3 months, $49 \%$ were women and a mean age of $55 \pm 15$ years. Twelve per cent (11.9; $95 \% \mathrm{Cl} 8.2$ to 15.4$)$ of patients had chronic pain at the 3-month follow-up. Controlling for age, sex and pain condition, patients with moderate or severe pain trajectories and those with only a severe pain trajectory were respectively 5.1 (95\% Cl 2.2 to 11.8$)$ and $8.2(95 \% \mathrm{Cl} 3.4$ to 20.0$)$ times more likely to develop chronic pain 3 months later compared with patients in the low final pain trajectories.

Conclusion Specific acute pain trajectories following an ED visit are closely related to the development of chronic pain 3 months later.

Trial registration number NCT02799004; Results.

\section{INTRODUCTION}

Studies assessing acute pain management after emergency department (ED) visits showed that a substantial number of patients
Strengths and limitations of this study

- First study to show an association between acute pain trajectories and chronic pain.

- Use of a group-based trajectory modelling to identify patients with different acute pain evolution.

- The low diary return rate could bias the representativeness of our sample.

- The convenience sample from one emergency department centre and the small sample size for less frequent pain conditions limit the generalisation of our results.

continue to experience pain even 7 days after discharge. ${ }^{1-3}$ Inadequate acute pain management can reduce the quality of life, cause unnecessary suffering, decrease productivity or academic performance ${ }^{4-6}$ and can often lead to the development of chronic pain. ${ }^{78}$

Several studies on ED discharged patients ${ }^{9-11}$ or on postsurgical follow-up ${ }^{12-14}$ showed that acute pain intensity at a specific time or its evolution has been associated with development of chronic pain 3, 6 or 12 months later. For instance, pain 1 week after ED discharge was independently associated with moderate to severe pain $(\mathrm{OR}=3.8) 3$ months later in patients with acute low back pain, ${ }^{9}$ while pain level at ED discharge in patients with musculoskeletal extremity injuries was related to chronic pain $(\mathrm{OR}=1.9) .{ }^{11}$ Parameters estimated by linear curve fitting (slope and intercept) from the acute pain evolution over 7 days have also been associated with chronic pain after surgery. ${ }^{12}$ However, in another study with patients presenting lower extremity injuries, only the first collected pain score (and not the pain evolution) was predictive of chronic pain 3 months later. ${ }^{10}$

Short-term pain resolution after an acute pain ED visit or surgical procedure has been generally described as a linear process. ${ }^{101215-17}$ 
However, this notion was recently challenged by studies using different statistical methodologies to illustrate non-linear patterns of acute pain evolution. ${ }^{18-20}$ Groupbased trajectory modelling (GBTM) is a statistical tool that identifies groups of patients with similar behavioural evolution over time without assuming the existence of a specific trend or number of groups. ${ }^{21}$ These new tools offer a more flexible approach of identifying linear or non-linear trajectories of pain evolution. ${ }^{22}$

Using GBTM, Okamoto et al showed that a 'severe pain' cluster was significantly associated with the presence of pain at the 6-month follow-up after breast cancer surgery $(\mathrm{OR}=9.4) .{ }^{20}$ Another study using latent class growth analysis showed that the high-intensity acute postoperative pain trajectory predicted chronic pain 6 months following knee replacement $(\mathrm{OR}=4.2){ }^{23}$

Because GBTM has been generally used in the context of postoperative pain, almost no data exist on the acute pain evolution of ED discharged patients using this methodology. However, in a recent prospective study ${ }^{24}$ investigating ED discharged patients with an opioid prescription, we found that acute pain evolved through six distinctive acute pain trajectories during a 14-day follow-up. The main objective of the present study was to examine the relationship between those trajectories and the presence of chronic pain 3 months later. We hypothesised that patients with moderate or severe pain intensity trajectories during the first 2 weeks after ED discharge will exhibit a higher risk of developing chronic pain 3 months later.

\section{MATERIALS AND METHODS}

\section{Patient and public involvement}

This research originated from the rising death toll from opioids overdose. However, neither the patients nor the public were involved in the design or conduct of the study.

\section{Study design and setting}

This is a prospective cohort study conducted in the ED of a tertiary care level 1 trauma centre and academic urban hospital with an affiliated emergency medicine residency programme and an annual census of approximately $65000 \mathrm{ED}$ visits (mostly adults). This research involved a 3-month follow-up from a larger cohort assessing the pain management of patients who received an opioid prescription after an ED visit for acute pain. ${ }^{25}$

\section{Participants}

Patients aged 18 years or older treated in the ED between June 2016 and July 2017 were identified 24/7 by ED physicians. We included patients with an acute pain condition present for less than 2 weeks (usual acute pain definition) ${ }^{26}$ and discharged from the ED with an opioid prescription. ED physicians generally used the WHO analgesic ladder to instruct patients how to manage their pain at home, but these instructions were not standardised. All ED physicians referred these patients to research nurses, who then verified inclusion and exclusion criteria, explained the study and obtained informed consent. This was a convenience sample as we were unable to reliably determine the number of patients missed by ED physicians (no electronic tracking system for outpatient prescriptions). We only excluded patients who did not speak French or English, were using opioid medication prior to the ED visit (last 2 weeks), stayed in the ED for more than 48 hours or with a history of cancer or chronic pain. For the present study, we retained only participants who completed the 2-week pain diary from a previous research assessing acute pain management of ED discharged patients. ${ }^{24}$

\section{Measures}

The complete patient recruitment procedure (flow chart), data collection, best model selection, handling of missing data and evaluation of the general fitness of the GBTM models have been previously described in a larger pain management study. ${ }^{24}$ Briefly, patients' demographic information, pain intensity at triage (11-point numeric rating scale (NRS)), arrival mode, triage priority and length of ED stay were extracted from our computerised medical system. Moreover, ED physicians recorded the final diagnosis, pain intensity at discharge (11-point NRS) and the prescribed pain medications. Patients received a 14-day diary in which they reported, at the end of each day, their daily average pain level on an 11-point NRS ranging from 0 to 10 , where 0 represents 'no pain at all' and 10 represents 'the worst imaginable pain'. Only the pain intensity at home was included in the trajectory analysis. We chose a 14-day follow-up because it is a reasonable time duration to monitor acute pain according to its definition. ${ }^{26}$ Moreover, it was also during this period that the pain medication need was met for a vast majority of patients $(88 \%)$ in our pilot study. ${ }^{27}$

The GBTM performed on the acute pain period of patients who completed the 14-day diary $(n=372)$ has been previously presented. ${ }^{24}$ The six-trajectory model demonstrated an overall very good fit adequacy. Each trajectory found with the GBTM analysis was named as a combination of its initial and final pain intensities. Two groups with linear trajectories had initial severe pain; one remained with severe pain during the 14 days (severesevere pain trajectory: $12.6 \%$ of the sample) while the other slowly diminished to a moderate pain intensity (severe-moderate pain trajectory: 26.3\%). The other four groups with cubic polynomial order trajectories had initial severe, moderate or mild pain that evolved to mild or no pain during the 14 days (collectively termed 'final low pain' trajectories). The representation of the six acute pain trajectories is reproduced in the online supplemental figure S1.

Three months after ED visit, patients were contacted (maximum of three attempts) by phone and were asked if they still suffered from the pain for which they went to the ED, using the same 11-point NRS as the diary. Definition of chronic pain differed greatly across 
epidemiological research. ${ }^{28}$ Based on previous studies, we defined patients as suffering from chronic pain if their pain intensity related to the initial health problem was $\geq 4$ at 3 months. ${ }^{911}$ The 3 -month time point was chosen because it generally defines the start of chronic pain. ${ }^{29}$ Study data were entered and managed using Research Electronic Data Capture, a secure, web-based tool hosted in the hospital. ${ }^{30}$

The quantity of opioid pills prescribed could not be analysed directly due to the particular potency and dosage of each different opioid. In order to compare the various opioid forms, each opioid was transformed into an oral morphine $5 \mathrm{mg}$ pill equivalent, ${ }^{31}$ using Berdine and Nesbit's ${ }^{32}$ method. A dosage of $3.33 \mathrm{mg}$ of oxycodone and $1.25 \mathrm{mg}$ of hydromorphone was considered equipotent to one $5 \mathrm{mg}$ morphine pill.

\section{Data analysis and statistics}

Baseline characteristics of included patients and those who were lost to follow-up are presented using descriptive statistics. Differences in median and in proportion were calculated with associated 95\% CIs. We used HodgesLehman estimates to calculate $95 \%$ CIs of median differences. Potential predictors of chronic pain at the 3-month follow-up (age, sex, pain condition, pain intensity at triage and at discharge, and pain trajectories) were compared using the same difference statistics. Two binary logistic regression models were used to assess if pain trajectories ('severe-moderate or severe-severe: yes/no' and 'severesevere: yes/no') were associated with chronic pain at follow-up controlling for age, sex and pain condition. We did not include pain intensity at ED discharge in the multivariable analysis because of its collinearity with pain trajectories. We grouped pain conditions into five categories as frequently reported in the $\mathrm{ED}^{33}$ : fracture, back or neck pain, other musculoskeletal pain (eg, sprain, strain, dislocation, contusion), renal colic and other pain complaints (eg, abdominal pain, abscess, burn, tooth pain). Alpha level was set at 0.05 , and these analyses were performed using SPSS V.23 (IBM).

\section{RESULTS}

\section{Study cohort description}

During the 1-year recruitment period, 372 patients completed the 2-week pain diary and included in the trajectory analysis. ${ }^{24}$ Of these, 67 patients $(18 \%)$ were lost at the 3-month follow-up, leaving 305 participants for analyses. Included patients and those lost to follow-up were similar on all baseline characteristics (table 1). Patients' median age was 53 years, $49 \%$ were female and median pain intensity at triage was 8 , decreasing to 5 at ED discharge. The median number of $5 \mathrm{mg}$ morphine pills prescribed at ED discharge was 30 .

\section{Association between group trajectories and chronic pain}

After 3 months, $12 \%$ (11.9; 95\% CI 8.2 to 15.4$)$ of patients had a pain intensity $\geq 4$ related to their initial health problem at the 3-month follow-up, thus meeting the criterion for chronic pain. These patients had higher pain intensity at ED discharge, were more often diagnosed with back/neck problems and less often with the 'other' pain condition and their acute pain intensity trajectories were more frequently severe-moderate or severe-severe compared with those without chronic pain at 3 months (table 2). Three out of four patients who developed chronic pain at 3 months followed a severe-moderate or severe-severe pain trajectory during the 14-day follow-up.

Controlling for age, sex and type of pain condition, patients with severe-moderate or severe-severe pain trajectories and those with severe-severe pain trajectory were respectively 5.1 (95\% CI 2.2 to 11.8 ) and 8.2 (95\% CI 3.4 to 20.0) times more likely to develop chronic pain at 3 months compared with the final low pain trajectories (table 3).

\section{DISCUSSION}

This prospective study demonstrated that a significant proportion $(12 \%)$ of patients suffering from acute pain conditions treated with opioids will eventually develop chronic pain 3 months after ED discharge. In agreement with our hypothesis, we also showed that patients with severe-moderate or severe-severe 14-day postdischarge pain trajectories were at risk of chronic pain 3 months later.

The incidence of chronic pain at 3 months (NRS $\geq 4$ ) observed in the present study is similar to the levels reported for ED discharged populations with back pain at 3 months $(16 \%)^{9}$ or with musculoskeletal extremity injuries at 6 months $(10 \%) .{ }^{11}$ This suggests that our sample is comparable to other ED populations and emphasises the importance of adequately treating the acute pain patient population, considering that a significant proportion of them will develop chronic pain. Our incidence $(12 \%)$ is lower than the prevalence of chronic pain reported in the general Canadian population (19\%). ${ }^{34}$ This could be explained by the fact that we excluded patients who were currently treated for chronic pain, included renal colic that should not evolve to chronic pain, selected only patients discharged with an opioid prescription and by the distinct chronic pain definition used in both studies.

In previous studies, high-intensity pain during the ED stay or at discharge has often been associated with chronic pain. ${ }^{11}$ However, as demonstrated in the pain intensity trajectories of online supplemental figure S1, two different groups of patients who had high initial pain intensity values rapidly (exponential function) resolved their pain to a complete recovery. In fact, these patients represent $35 \%$ of the sample, which is non-negligible, and have less chance of developing chronic pain. Therefore, looking at the evolution of pain intensity in the first weeks can be helpful to identify people at risk of chronic pain. Furthermore, trajectories, as those produced by GBTM to characterise patterns of pain evolution, can be used even with missing data. In the present study, the pain intensity 
Table 1 Baseline characteristics of included patients and those who were lost to follow-up

\begin{tabular}{|c|c|c|c|}
\hline Baseline characteristics & Included ( $n=305)$ & Lost to follow-up ( $n=67)$ & Difference $(95 \% \mathrm{Cl})$ \\
\hline Age, median (IQR, range), years & $53(43-66,18-95)$ & $57(44-66,18-90)$ & $-4(-9$ to 1$)$ \\
\hline Sex, n (\%), women & $150(49)$ & $37(55)$ & $-6(-19$ to 7$)$ \\
\hline By self & $256(84)$ & $51(76)$ & \\
\hline By ambulance & $49(16)$ & $16(24)$ & \\
\hline ED treatment section, $\mathrm{n}(\%)$ & & & $9(-3$ to 22$)$ \\
\hline Ambulatory & $210(69)$ & $40(60)$ & \\
\hline On stretcher & $95(31)$ & $27(40)$ & \\
\hline \multicolumn{4}{|l|}{ Type of pain condition, $n(\%)$} \\
\hline Renal colic & $51(17)$ & $10(15)$ & $2(-7$ to 11$)$ \\
\hline Other pain* & $50(16)$ & $4(6)$ & 10 (3 to 17$)$ \\
\hline Acetaminophent prescription at ED discharge, $\mathrm{n}(\%)$ & $216(71)$ & $48(72)$ & $1(-11$ to 13$)$ \\
\hline NSAID prescription at ED discharge, $\mathrm{n}(\%)$ & $130(43)$ & $24(36)$ & $7(-6$ to 20$)$ \\
\hline \multicolumn{4}{|l|}{ Opioid prescription type at ED discharge, $\mathrm{n}(\%)$} \\
\hline Morphine & $130(43)$ & $28(42)$ & $1(-12$ to 14$)$ \\
\hline Oxycodone & $124(41)$ & $23(34)$ & $7(-6$ to 20$)$ \\
\hline Hydromorphone & $51(17)$ & $16(24)$ & $-7(-18$ to 4$)$ \\
\hline $\begin{array}{l}\text { Number of morphine } 5 \mathrm{mg} \text { equivalent pills prescribed, } \\
\text { median (IQR) }\end{array}$ & $30(20-48)$ & $30(16-45)$ & $0(-5$ to 5$)$ \\
\hline
\end{tabular}

*For example, abdominal pain, abscess, burn, tooth pain.

†Acetaminophen was always prescribed separately from opioids.

ED, emergency department; NSAID, non-steroidal anti-inflammatory drug.;

data at day 14 were missing for $20 \%$ of the participants, although patients could still be associated to a specific pain trajectory.

Contrary to the linear fitting used by Chapman and others $^{10} 1215-17$ which assumes that acute pain intensities evolve linearly with time for all patients, GBTM used in the present study offers a more flexible approach. Four pain intensity trajectories, representing $61 \%$ of the patients, were non-linear in their evolution. However, two other trajectories were linear, with patterns similar to the ones observed by Chapman et $a l^{16}$ : the first one with almost no decrease in pain intensity while the second one had a steeper slope but still ended the follow-up period with moderate pain intensity. These two patient groups present risk of developing chronic pain in the future, particularly the first one. After controlling for confounders, the risk of developing chronic pain for patients in that group was close $(\mathrm{OR}=8.2)$ to the risk of having pain at 6 months in the breast cancer surgery study ${ }^{20}(\mathrm{OR}=9.4)$ using the same GBTM model. However, the breast cancer surgery study identified three different trajectories of acute pain intensity resolution while we observed six. The different types of pain conditions encountered in the ED (fracture, musculoskeletal, renal colic, back pain) could presumably explain the more complex patterns of pain resolution observed in the present study.

Despite receiving aggressive treatment for their acute pain (every patient received an opioid prescription and $80 \%$ of them consumed opioids during the acute period), almost $40 \%$ of the patients remained with severe or moderate pain intensity during the 14-day follow-up. Seventy-five percent of patients who develop chronic pain at 3 months belonged to either one of these two pain trajectories. It is also important to remember that patients already suffering from chronic pain were excluded from the present study. Acute pain intensity trajectories could represent an interesting tool to identify patients at risk of developing chronic pain.

\section{Limitations}

Several limitations could restrict the conclusions drawn from the present study. This was a single site study, carried 
Table 2 Potential predictors of chronic pain (pain intensity $\geq 4$ ) at the 3-month follow-up

\begin{tabular}{|c|c|c|c|}
\hline Baseline characteristics & Chronic pain $(n=36)$ & No chronic pain $(n=269)$ & Difference $(95 \% \mathrm{Cl})$ \\
\hline Age, median (IQR), years & $52(41-68)$ & $54(43-66)$ & $-2(-8$ to 4$)$ \\
\hline Sex, n (\%), women & $21(58)$ & $129(48)$ & $10(-7$ to 28$)$ \\
\hline Pain intensity (0-10 scale) at ED discharge, median (IQR) & $7(5-8)$ & $5(2-7)$ & $2(1$ to 3$)$ \\
\hline \multicolumn{4}{|l|}{ Type of pain condition, $\mathrm{n}(\%)$} \\
\hline Other musculoskeletal pain & $12(33)$ & $61(23)$ & $10(-2$ to 22$)$ \\
\hline Renal colic & $0(0)$ & $51(19)$ & $-19(-23$ to -15$)$ \\
\hline Other pain* & $3(8)$ & $47(18)$ & $-10(-18$ to -2$)$ \\
\hline $\begin{array}{l}\text { With severe-moderate or severe-severe acute pain } \\
\text { trajectories, } \mathrm{n}(\%)\end{array}$ & $27(75)$ & $92(34)$ & 41 (24 to 58$)$ \\
\hline
\end{tabular}

${ }^{\star}$ For example, abdominal pain, abscess, burn, tooth pain.

ED, emergency department.

in an urban, academic, tertiary care hospital and the findings may not be generalisable to other health settings. The low diary return rate $(51 \%)$ during the acute pain period could also bias the representativeness of our sample. However, we did not find important differences between patients who completed the 3-month follow-up and those who did not. The convenience sample limits the generalisation of our results, as a selection bias could exist. Nevertheless, patients were recruited 24/7, and consecutive recruitment was limited only by the fact that the investigators could not determine the number of patients missed by ED physicians (no electronic tracking system for outpatient prescriptions). Moreover, identification of eligible patients might have been influenced by crowding, staffing and treatment priorities. In addition, we only selected patients who were discharged with an opioid prescription, including patients with similar types of pain and intensity but without opioid prescription could produce different results.

Patients regrouped in different types of pain conditions could have different pain intensity course in time. However, these types of pain conditions were associated with specific acute pain trajectories in our previous work. ${ }^{24}$ Also, the 'other' pain category was composed of different pain aetiologies and it is therefore possible that these pain conditions could generate different acute pain

Table 3 Results of univariate and multivariable logistic regressions to predict chronic pain (pain intensity $\geq 4$ ) at the 3 -month follow-up

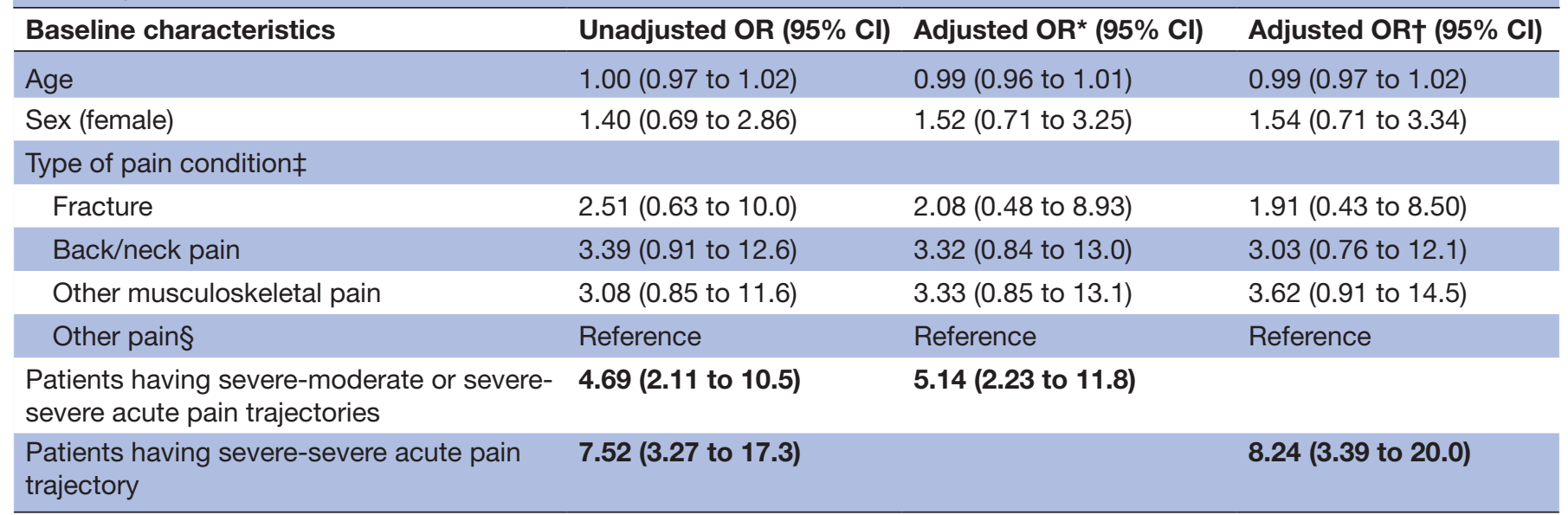

ORs in bold are significant at $\mathrm{p}<0.001$.

${ }^{*}$ Adjusted for all predictive variables including severe-moderate or severe-severe acute pain trajectories.

†Adjusted for all predictive variables including severe-severe acute pain trajectory.

$\ddagger$ Patients with renal colic were removed since none of them developed chronic pain.

$\S$ For example, abdominal pain, abscess, burn, tooth pain. 
trajectories. Furthermore, some results should be interpreted with caution. We do not have information on the delay between the onset of pain and the ED visit, so we were unable to evaluate the impact of untreated pain. The relatively small number of patients with chronic pain at the 3-month follow-up limits our power to identify specific patient characteristics that could be significant, especially the type of pain condition that contained several categories (large CIs). Finally, the specific acute pain trajectories found in our previous work have not been validated elsewhere and we did not control for factors known to affect chronic pain development: history of chronic pain, anxiety, depression and pain catastrophising. ${ }^{35}$

\section{CONCLUSIONS}

In summary, specific acute pain trajectories following an ED visit are closely related to the development of chronic pain 3 months later. Almost $40 \%$ of patients belong to trajectories shown to be associated with a high risk for developing chronic pain (severe-moderate or severe-severe) and $75 \%$ of patients who actually evolved to chronic pain had followed those specific acute pain trajectories. These acute pain trajectories could represent an interesting tool to prevent pain chronicity.

Acknowledgements The authors would like to thank Martin Marquis and Dominique Petit for their contributions to manuscript revision.

Contributors RD and JMC conceived the study and obtained research funding. All authors contributed to the final protocol and data interpretation. JP was responsible for data management and statistical analysis. RD drafted the manuscript. AC, EP, $\mathrm{JM}, \mathrm{JL}$ and GL contributed substantially to its revision. All authors approved the final manuscript as submitted and have agreed to be accountable for all aspects of the work.

Funding This study was supported by the FRSQ (No 29307).

Competing interests None declared.

Patient consent for publication Obtained.

Ethics approval The 'Comité d'éthique de la recherche du CIUSSS du Nordde-l'Île-de-Montréal' review board approved this study including the 3-month follow-up.

Provenance and peer review Not commissioned; externally peer reviewed.

Data availability statement Data are available upon reasonable request. Original data set found in the manuscript is available upon request to the corresponding author.

Supplemental material This content has been supplied by the author(s). It has not been vetted by BMJ Publishing Group Limited (BMJ) and may not have been peer-reviewed. Any opinions or recommendations discussed are solely those of the author(s) and are not endorsed by BMJ. BMJ disclaims all liability and responsibility arising from any reliance placed on the content. Where the content includes any translated material, BMJ does not warrant the accuracy and reliability of the translations (including but not limited to local regulations, clinical guidelines, terminology, drug names and drug dosages), and is not responsible for any error and/or omissions arising from translation and adaptation or otherwise.

Open access This is an open access article distributed in accordance with the Creative Commons Attribution Non Commercial (CC BY-NC 4.0) license, which permits others to distribute, remix, adapt, build upon this work non-commercially, and license their derivative works on different terms, provided the original work is properly cited, appropriate credit is given, any changes made indicated, and the use is non-commercial. See: http://creativecommons.org/licenses/by-nc/4.0/.

\section{ORCID iD}

Raoul Daoust http://orcid.org/0000-0001-6507-0198
REFERENCES

1 Chang AK, Bijur PE, Munjal KG, et al. Randomized clinical trial of hydrocodone/acetaminophen versus codeine/acetaminophen in the treatment of acute extremity pain after emergency department discharge. Acad Emerg Med 2014;21:227-35.

2 Larsen MJ, Fosnocht DE, Swanson ER. Pain management after discharge from the emergency department. Ann Emerg Med 2004;44:S88.

3 Johnston CC, Gagnon AJ, Pepler CJ, et al. Pain in the emergency department with one-week follow-up of pain resolution. Pain Res Manag 2005;10:67-70.

4 Pavlin DJ, Chen C, Penaloza DA, et al. A survey of pain and other symptoms that affect the recovery process after discharge from an ambulatory surgery unit. J Clin Anesth 2004;16:200-6.

5 Morrison RS, Magaziner J, McLaughlin MA, et al. The impact of post-operative pain on outcomes following hip fracture. Pain 2003;103:303-11.

6 Voerman JS, de Klerk C, Vander Heyden KM, et al. Pain is associated with poorer grades, reduced emotional well-being, and attention problems in adolescents. Clin J Pain 2017;33:44-50.

7 Young Casey C, Greenberg MA, Nicassio PM, et al. Transition from acute to chronic pain and disability: a model including cognitive, affective, and trauma factors. Pain 2008;134:69-79.

8 Sinatra R. Causes and consequences of inadequate management of acute pain. Pain Med 2010;11:1859-71.

9 Friedman BW, Conway J, Campbell C, et al. Pain one week after an emergency department visit for acute low back pain is associated with poor three-month outcomes. Acad Emerg Med 2018;25:1138-45.

10 Griffioen MA, Greenspan JD, Johantgen M, et al. Acute pain characteristics in patients with and without chronic pain following lower extremity injury. Pain Manag Nurs 2017;18:33-41.

11 Pierik JGJ, IJzerman MJ, Gaakeer MI, et al. Incidence and prognostic factors of chronic pain after isolated musculoskeletal extremity injury. Eur J Pain 2016;20:711-22.

12 Althaus A, Arránz Becker O, Neugebauer E. Distinguishing between pain intensity and pain resolution: using acute post-surgical pain trajectories to predict chronic post-surgical pain. Eur J Pain 2014;18:513-21.

13 Lavand'homme PM, Grosu I, France M-N, et al. Pain trajectories identify patients at risk of persistent pain after knee arthroplasty: an observational study. Clin Orthop Relat Res 2014;472:1409-15.

14 Gilron I, Vandenkerkhof E, Katz J, et al. Evaluating the association between acute and chronic pain after surgery: impact of pain measurement methods. Clin J Pain 2017;33:588-94.

15 Chapman CR, Donaldson GW, Davis JJ, et al. Improving individual measurement of postoperative pain: the pain trajectory. $J$ Pain 2011;12:257-62

16 Chapman CR, Fosnocht D, Donaldson GW. Resolution of acute pain following discharge from the emergency department: the acute pain trajectory. J Pain 2012;13:235-41.

17 Sipilä RM, Haasio L, Meretoja TJ, et al. Does expecting more pain make it more intense? Factors associated with the first week pain trajectories after breast cancer surgery. Pain 2017;158:922-30.

18 Downie AS, Hancock MJ, Rzewuska M, et al. Trajectories of acute low back pain: a latent class growth analysis. Pain 2016;157:225-34.

19 Kannampallil T, Galanter WL, Falck S, et al. Characterizing the pain score trajectories of hospitalized adult medical and surgical patients: a retrospective cohort study. Pain 2016;157:2739-46.

20 Okamoto A, Yamasaki M, Yokota I, et al. Classification of acute pain trajectory after breast cancer surgery identifies patients at risk for persistent pain: a prospective observational study. J Pain Res 2018;11:2197-206.

21 Nagin DS, Odgers CL. Group-Based trajectory modeling in clinical research. Annu Rev Clin Psychol 2010;6:109-38.

22 Daoust R, Emond M, Bergeron E, et al. Risk factors of significant pain syndrome 90 days after minor thoracic injury: trajectory analysis. Acad Emerg Med 2013;20:1139-45.

23 Thomazeau J, Rouquette A, Martinez V, et al. Predictive factors of chronic post-surgical pain at 6 months following knee replacement: influence of postoperative pain trajectory and genetics. Pain Physician 2016;19:E729-41.

24 Daoust R, Paquet J, Cournoyer A, et al. Acute pain resolution after an emergency department visit: a 14-day trajectory analysis. Ann Emerg Med 2019;74:224-232. doi:10.1016/j.annemergmed.2019.01.019. [Epub ahead of print: 20 Feb, 2019].

25 Daoust R, Paquet J, Cournoyer A, et al. Quantity of opioids consumed following an emergency department visit for acute pain: a 
Canadian prospective cohort study. BMJ Open 2018:8:e022649.

26 Bonica JJ. The need of a taxonomy. Pain 1979;6:247-8.

27 Daoust R, Paquet J, Cournoyer A, et al. Quantity of opioid to prescribe for acute pain to limit misuse after emergency department discharge. Acad Emerg Med 2017;24:S225.

28 Steingrímsdóttir Ólöf Anna, Landmark T, Macfarlane GJ, et al. Defining chronic pain in epidemiological studies: a systematic review and meta-analysis. Pain 2017;158:2092-107.

29 King Wet al. Acute Pain, Subacute Pain and Chronic Pain. Berlin, Heidelberg: Springer Berlin Heidelberg, 2007.

30 Harris PA, Taylor R, Thielke R, et al. Research electronic data capture (REDCap)--a metadata-driven methodology and workflow process for providing translational research informatics support. $J$ Biomed Inform 2009;42:377-81.
31 O'Neil JT, Wang ML, Kim N, et al. Prospective evaluation of opioid consumption after distal radius fracture repair surgery. Am J Orthop 2017;46:E35-40.

32 Berdine HJ, Nesbit SA. Equianalgesic dosing of opioids. J Pain Palliat Care Pharmacother 2006;20:79-84.

33 Hoppe JA, Nelson LS, Perrone J, et al. Opioid prescribing in a cross section of US emergency departments. Ann Emerg Med 2015;66:253-9.

34 Schopflocher D, Taenzer P, Jovey R. The prevalence of chronic pain in Canada. Pain Res Manag 2011;16:445-50.

35 Rushton AB, Evans DW, Middlebrook N, et al. Development of a screening tool to predict the risk of chronic pain and disability following musculoskeletal trauma: protocol for a prospective observational study in the United Kingdom. BMJ Open 2018;8:e017876. 